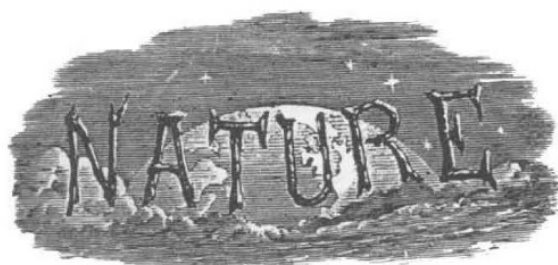

SATURDAY, FEBRUARY 4, I933

No. 3301

CONTENTS

Petroleum Technology and Chemical Industry. By H. B. M.

Age of Retirement in India

Evolution and Mechanism of Hearing

The Spiders of Denmark. By T. H. S.

Diphtheria

Surface Catalysis

Short Reviews

Edmond Halley. By Dr. Allan Ferguson

Recent Radio Research

Obituary :

Prof. James Johnstone • • • • I57

Prof. C. M. Thompson. By A. A. R. : : 158

News and Views $\quad . \quad+\quad . \quad . \quad . \quad 159$

Letters to the Editor :

The Whale Shark in the Waters around Ceylon.

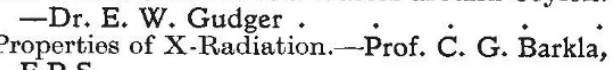
F.R.S.

Carbonyls of Lithium, Rubidium and Cæsium. -Dr. T. G. Pearson . . Systems of Four Immiscible Liquid Layers.-

E. Lester Smith
Vacant Positions in the Iron Lattice of Pyrrhotite.-Prof. Gunnar Hägg

Positive Ion Emission from Oxide Catalysts.Dr. C. F. Powell and Luang Brata .

Fusion of Carbon.-A. Egerton, F.R.S., and M. Milford

Liesegang Rings.-Dr. Ërnest S. Hedges

Nitrogen Fixation in the Genus Lolium.R. Brown . . . . . . Ambiguity in Sign of Spearman's General

Factor.-Prof. H. T, H. Piaggio
Spectra of Bromine : Br V, VII and ${ }^{*} \mathrm{IV} .-$ A. S. Rao and Dr, K. R. Rao

Research Items.

Instability of Liquid Surfaces. By Dr. L. Rosenhead I75

Density and Egg-Laying in Flies ..$~ I 76$

U • • • I76

University and Educational Intelligence . . . I77

Calendar of Nature Topics . . . : . 177

Societies and Academies . . . . . $\quad$ I78

Forthcoming Events . . . . . . I80

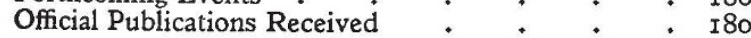

Editorial and Publishing Offices :

MACMILLAN \& CO., LTD.

ST. MARTIN'S STREET, LONDON, W.C.2

Telephone Number: WHITEHALL 883I

I elegraphic Address : PHUSIS, LESQUARE, LONDON

Advertisements should be addressed to

T. C. Scott \& Son Ltd., 63 Ludgate Hill, London, E.C.4 Telephone Number : City I266

\section{Petroleum Technology and Chemical Industry}

TF we survey the course of evolution of petroleum technology, particularly as it concerns the treatment, refining and utilisation of crude oil and its products, it is an impressive fact that despite a magnitude of growth and ramifications of the industry it supports in modern life, equally an obvious dependence throughout on the functions of certain applied major sciences, it has long maintained, outwardly at all events, a remarkable measure of autonomy. No one ever seriously suggested, because chemistry and physics, for example, enter largely into the technique of manufacture of innumerable products from the raw material, that this technology is ipso facto an offspring of co-ordinated influences of these or any other sciences. On the contrary, oil technology has grown in an almost unique fashion. It has been urged by an overwhelming but universal impulse. It has rapidly strengthened from an innate knowledge of its inherent power as a world force, casually absorbing, but diligently applying, just those established principles of appropriate natural science as would meet its needs. It has known few of the struggles of just as important, but none the less subservient, industrial technologies.

No one science nor the more mundane interests of international, economic and political life, which petroleum has profoundly influenced in latter years, can legitimately claim any fundamental control over the technology even now. There are signs, however, that this order of things is destined to change, if indeed the change is not now actually taking place.

In a welter of conflicting difficulties through which the industry has been and still is passing, certain facts stand out as pre-eminent in any consideration of the situation. Over-production, not only of crude oil but also of many of its products ; waste; curtailed consumption ; increasing competition with commodities serving similar purposes but derived from different raw materials; vicissitudes of current international commerce; all these combine to create within the industry an acute self-consciousness of stifled activity, probably for the first time in its history. The repercussions of this have not been without their corresponding reaction on the technology. No one can really see far ahead with precision. Even the convictions of those who profess to know carry little more than temporary weight, since they seem to lack firm 
and definite foundation in a much disturbed ground.

Into this bewildering maze of circumstances there has been flung, with considerable force recently, the challenge of synthetic oil from hydrogenation process. What is the significance of this incursion? It is inconceivable, aside from all economic argument, that this factor in the situation can be other than one to be seriously reckoned with; it is disturbing even now ; it is bound to be formidable ultimately in the petroleum industry, and to have far-reaching consequences on the technical operations involved therein.

The history of chemical industry is rich in examples of new processes in which the established commercial success was achieved among the ruins of discarded doubts and scepticisms at the outset. Hydrogenation is a long-tried process ; it has, as a technical procedure, been brought to a high state of efficiency. It is chemical engineering at its best. Oil production from coal, whether by this or by any other means is, and must inevitably be, on whatever scale achieved, a product of chemical industry. To this extent, the product differs fundamentally from anything realised by the petroleum industry.

The coal industry per se is non-existent in the same sense in which we contemplate and assess the activities of the oil industry to-day. It discarded individuality long ago in favour of secondhand recognition through the medium of dependent products such as gas, coal-tar, dyes and allied substances, the enormous developments of which not only built up relevant commercial activities, but also have contributed more to the growth of chemical industry as a whole than probably any other branch of it. Hydrogenated coal-oil when it arrives as an accepted economic commodity will simply add another weapon to the already powerful array of forces which chemistry commands in the sway of modern civilisation.

The moral to the petroleum industry in general, and to the technology in particular, is surely obvious. There has for long been the broadest possible overlap between research within the petroleum and chemical industries, at least as technically interpreted, and where basic substances common to both have been involved. Research, temporarily retarded as it may have been by prevalent conditions, has none the less forged ahead in chemical industry, as keenly animated as ever by the desire to conquer fresh fields and produce new outlets for natural resources at the present time only partially or extravagantly exploited. The trend of petroleum technology, if it is to compete with the incidence of an independent and biased chemical industry, must, apart from the actual winning of oil, inevitably lead in the direction of finding new and extended uses for its raw material and basic products.

It is insufficient to point to a succession of highly refined products of crude oil such as petroleum, paraffin, lubricating and fuel oils, wax and asphaltic bitumen-the high standard of production of which to-day is freely acknowledged -as though these represent monuments to final achievement. There can be no such finality, and research must aim far beyond the mere improvement of technique of production, the multiplicity of types and qualities of distillates, and the goal of supplying markets with what they have been accustomed.

In point of fact, the domain of petroleum technology is no longer inviolable; and if it does not of its own initiative expand actively into the realm of chemical industry, then assuredly will the latter gradually stretch the tide-mark of overlap until the merger is complete.

Petroleum, like coal, is a wasting asset. It is no longer the prerogative of the oil industry alone and, as a natural resource still possessing immense latent possibilities of more efficient development, it must come into line with other basic raw materials and be subject to that vigorous independent investigation which is afforded by intensive chemical research. Only in this way will it avoid some of the calamitous happenings which have led to the acute problems of efficient coal exploitation and utilisation, for which, it is to be noted, chemical industry has gone a long way to find a practical and economic solution. H. B. M.

\section{Age of Retirement in India}

$\mathrm{U}$ NDER the title "The Fifty-five Year Rule", the November issue of the Indian monthly, Current Science, contains a long leading article advocating the abolition of retirement from educational posts at the age of fifty-five, as is now compulsory under the fundamental rules, and the raising of the age limit to sixty years in the first instance, or making such appointments for life. We have read the article with some surprise, since we are convinced that the concensus of opinion of 